\title{
Determinants of exacerbation risk in patients with COPD in the TIOSPIR study
}

This article was published in the following Dove Press journal:

International Journal of COPD

\section{Peter MA Calverley' \\ Kay Tetzlaff ${ }^{2}$ \\ Daniel Dusser ${ }^{3}$ \\ Robert A Wise ${ }^{4}$ \\ Achim Mueller ${ }^{5}$ \\ Norbert Metzdorf ${ }^{2}$ \\ Antonio Anzueto ${ }^{6}$}

'Clinical Science Centre, Institute of Ageing and Chronic Disease, University of Liverpool, Liverpool, UK; ${ }^{2}$ Respiratory Medicine, Boehringer Ingelheim Pharma GmbH, Ingelheim am Rhein, Germany; ${ }^{3}$ Department of Pneumology, Hôpital Cochin, Université Paris Descartes, Sorbonne Paris Cité, Paris, France; ${ }^{4}$ Division of Pulmonary and Critical Care Medicine, Department of Medicine, Johns Hopkins University School of Medicine, Baltimore, MD, USA; ${ }^{5}$ Biostatistics and Data Sciences Europe, Boehringer Ingelheim Pharma $\mathrm{GmbH}$, Biberach an der Riss, Germany; ${ }^{6}$ Pulmonary Medicine and Critical Care, University of Texas Health Sciences Center and South Texas Veterans' Health Care System, San Antonio, TX, USA
Correspondence: Peter MA Calverley Clinical Science Centre, Institute of Ageing and Chronic Disease, University of Liverpool, Longmoor Lane, Liverpool L9 7AL, UK

Tel +44 I5I 5295886

$\mathrm{Fax}+44$ I5I 5295888

Email pmacal@liverpool.ac.uk
Background: Exacerbation history is used to grade the risk of COPD exacerbation, but its reliability and relationship to other risk factors and prior therapy is unclear. To examine these interrelationships, we conducted a post hoc analysis of patients in the TIOSPIR trial with $\geq 2$ years' follow-up or who died on treatment.

Patients and methods: Patients were grouped by their annual exacerbation rate on treatment into nonexacerbators, infrequent, and frequent exacerbators (annual exacerbation rates $0, \leq 1$, and $>1$, respectively), and baseline characteristics discriminating among the groups were determined. We used univariate and multivariate analyses to explore the effect of baseline characteristics on risk of exacerbation, hospitalization (severe exacerbation), and death (all causes).

Results: Of 13,591 patients, 6,559 (48.3\%) were nonexacerbators, 4,568 (33.6\%) were infrequent exacerbators, and 2,464 (18.1\%) were frequent exacerbators; $45 \%$ of patients without exacerbations in the previous year exacerbated on treatment. Multivariate analysis identified baseline pulmonary maintenance medication as a predictive factor of increased exacerbation risk, with inhaled corticosteroid treatment associated with increased exacerbation risk irrespective of exacerbation history.

Conclusion: Our data confirm established risk factors for exacerbation, but highlight the limitations of exacerbation history when categorizing patients and the importance of prior treatment when identifying exacerbation risk.

Keywords: COPD, exacerbation, frequent exacerbators

\section{Plain-language summary}

Patients with COPD may experience times when symptoms suddenly get worse, known as exacerbations. These events contribute to progression of the disease, and make patients feel worse. People who have had a lot of exacerbations in the past are most at risk of having more exacerbations. In this study, researchers looked at what factors other than the number of past exacerbations might predict which patients are most likely to have an exacerbation. The researchers used results from a clinical trial that included more than 17,000 patients with COPD who were followed for 2-3 years. The results showed that in addition to history of exacerbation, the medications that patients were prescribed before they entered the trial also predicted how likely they were to have an exacerbation. This is probably because patients who are not doing well and most at risk of having an exacerbation are more likely to be prescribed certain medications. Overall, this study confirms that patients who have had more exacerbations in the past are at greater risk of exacerbations in the future, and shows that patients who require more medications for their COPD are at higher risk of exacerbations.

\section{Introduction}

Exacerbations of symptoms sufficient to warrant treatment with antibiotics and/or systemic corticosteroids (CSs) and/or hospitalization contribute to health-status 
impairment and disease progression in patients with COPD. ${ }^{1,2}$ Multiple reports in different COPD populations have found that exacerbations are more likely if the patient reports previous events, is more breathless, and has poor lung function, ${ }^{3-5}$ although the importance of a history of chronic bronchitis as a predictor of exacerbations is less clear. ${ }^{5,6}$ The data identifying these risk factors for exacerbations derive largely from observational cohorts or database studies where treatment choices reflect routine clinical practice.

To date, relatively little attention has been paid to the relationship of baseline treatment to the risk of subsequent exacerbation of COPD. Extensive randomized controlled trial data show that inhaled long-acting muscarinic antagonists (LAMAs), long-acting $\beta_{2}$-agonists (LABAs), and LABA-inhaled CS (ICS) combinations reduce the risk of exacerbations..$^{7-9}$ Further studies have shown that LAMAs are more likely to be effective than LABAs in preventing exacerbation, irrespective of whether LABA is administered once daily ${ }^{10}$ or twice daily. ${ }^{11}$ Whether the same risk factors operate when all patients are treated with these drugs is not yet clear. Moreover, it is not known whether treatment intensity, which is often used as a surrogate for disease severity in patients with asthma, ${ }^{12}$ is a marker of disease severity in COPD.

To address these problems, we examined data from the TIOSPIR trial, ${ }^{13,14}$ the largest long-term, randomized, double-blind, double-dummy, parallel-group trial in patients with COPD performed to date. We wished to establish whether use of LABAs and ICSs could be used as a surrogate marker for increased exacerbation risk in patients with COPD treated with tiotropium. We also sought to examine whether clinical and demographic variables that have been shown to be risk factors for exacerbations would pertain to a large international COPD population using tiotropium maintenance therapy.

\section{Patients and methods}

\section{Study design}

In TIOSPIR, 17,135 patients with COPD were randomized and treated in a double-blind, parallel-group, event-driven trial with follow-up of 2-3 years. Patients were randomized to once-daily tiotropium Respimat 5 or $2.5 \mu \mathrm{g}$, or once-daily tiotropium HandiHaler $18 \mu \mathrm{g}$ (both Boehringer Ingelheim, Ingelheim am Rhein, Germany). The trial design and methodology have been published previously. ${ }^{13}$ TIOSPIR was performed in accordance with the provisions of the Declaration of Helsinki, and the study protocol and procedures were approved by relevant institutional review boards and ethics committees (independent ethics committee Johns Hopkins
Medicine Institutional Review Board, Baltimore, MD, USA). All the patients provided written informed consent.

\section{Study population}

All participants had a diagnosis of COPD with a postbronchodilator forced expiratory volume in 1 second $\left(\mathrm{FEV}_{1}\right) \leq 70 \%$ predicted, an $\mathrm{FEV}_{1}$ :forced vital capacity (FVC) ratio $\leq 0.7$, were aged $\geq 40$ years, had been clinically stable for at least 6 weeks, and had $\geq 10$ pack-years of smoking history. Patients with concomitant cardiac disease were included, unless they had a recent history of myocardial infarction, cardiac arrhythmia, or hospitalization for heart failure. Patients were excluded if they had a history of significant respiratory diseases other than COPD, including asthma.

\section{Assessments}

The study period was dependent on the number of fatal events observed (event-driven trial). Visits occurred at weeks 0, 6, and 12 , and then every 12 weeks for the duration of the trial. At the first visit, concomitant medication use and medical history were noted, as was exacerbation history. Hospitalization due to COPD in the year prior to enrolment was not collected. At all visits, information about exacerbations and their treatment, including the need for hospitalization, were recorded. Vital status during the trial period was obtained in $99.7 \%$ of participants. Causes of death were adjudicated by an independent mortality adjudication committee.

COPD exacerbations were defined as a worsening of two or more major respiratory symptoms (dyspnea, cough, sputum, chest tightness, or wheezing) lasting $\geq 3$ days and requiring specified treatment changes. Moderate exacerbations required a prescription for antibiotics, systemic CSs, or both (with no hospitalization); severe exacerbations required hospitalization. Fatal COPD exacerbations were those with fatal outcome. The onset of exacerbation was defined as the onset of the first reported symptom; the end of exacerbation was decided by the investigator, based on clinical judgment (GOLD grouping was determined according to 2011 guidelines, which classified patients' risk by airflow limitation, symptoms, and exacerbations). ${ }^{15}$

\section{Statistical analysis}

The tiotropium-treatment arms were pooled for this post hoc analysis, as there were no differences between treatments for the primary outcomes (exacerbations and mortality). ${ }^{14}$ Patients were categorized by their annual exacerbation rate on treatment into the following frequency groups: nonexacerbators, infrequent exacerbators (annual exacerbation 
rate $>0$ and $\leq 1$ ), and frequent exacerbators (annual exacerbation rate $>1$ ). Patients were also categorized by the number of reported prestudy exacerbations (exacerbation history 0,1 , and $>1$ in the year before the study). In addition, we analyzed patients with severe exacerbations (exacerbations associated with hospitalization) and those with a fatal exacerbation.

Baseline characteristics discriminating between patients in the exacerbation groups (either prestudy or on treatment) were identified using descriptive statistics (differences between groups were signified by nominal $P$-values established using the Kruskal-Wallis test and the $\chi^{2}$ test). Furthermore, prognostic characteristics of exacerbation, hospitalization due to COPD exacerbation, and death (all-cause) were identified by univariate and multivariate Cox regression analyses, with results shown as forest plots.

The importance of factors added to the models was assessed by means of likelihood ratio tests. The effect of exacerbation history, LABA, and ICS use at baseline on exacerbations and death was investigated by Cox regression models with covariates for postbronchodilator $\mathrm{FEV}_{1}$ and smoking status at baseline. Time to event according to exacerbation history and ICS use at baseline are shown as Kaplan-Meier plots. To ensure that there was sufficient time for recurrent events to occur, we restricted the analysis to individuals with $\geq 2$ years of clinical observation (follow-up) or who had died within that period.

\section{Results \\ Study population}

Of the 17,135 patients who received tiotropium, 13,591 were followed for $\geq 2$ years or died during the study. In this group, $6,559(48.3 \%)$ had no exacerbations during the trial, 4,568 $(33.6 \%)$ were infrequent exacerbators (annual exacerbation rate $>0$ and $\leq 1)$, and 2,464 (18.1\%) were frequent exacerbators (annual exacerbation rate $>1$ ). A severe exacerbation requiring hospitalization was reported in 2,002 (14.7\%) of these patients, and $120(0.9 \%)$ patients experienced a fatal exacerbation (Table 1, continued in Table S1). In the year before randomization, 7,022 (51.7\%) patients had no exacerbations, 3,902 (28.7\%) had one exacerbation, and 2,667 $(19.6 \%)$ had more than one exacerbation (Table S2).

\section{Risk factors by exacerbation frequency and severity (hospitalized and fatal exacerbation) \\ Baseline demographics}

Baseline characteristics, including smoking history and bodymass index (BMI), were similar among the different groups whether defined by exacerbation rate on treatment (Table 1) or pretreatment (number of exacerbations reported in the preceding year; Table S2). The proportion of female patients was highest in the frequent-exacerbator group compared with the other exacerbation groups. Patients aged $\geq 60$ years had more exacerbations on treatment than patients $<60$ years of age (Table 1 ), although patients aged $\geq 60$ years were more likely to report no exacerbation in the year prior to the trial compared with younger ( $<60$ years) patients (Table S2). Patients most likely to have a fatal exacerbation were male and $\geq 70$ years old (Table 1 , Figure 1 ).

\section{Baseline lung function, exacerbation history, and COPD symptoms}

Baseline spirometry and exacerbation history showed a gradation across the on-treatment exacerbation-frequency group (being worst in frequent exacerbators), as did GOLD staging (I-IV), GOLD grouping (A-D), and breathlessness (Table $\mathrm{S} 1$ ). However, $13 \%$ of patients without a pretreatment exacerbation in the year before the study became frequent exacerbators during the trial (Figure 2). The presence of sputum-producing cough (chronic bronchitis for $>3$ months over 2 years) was consistent across these groups. When patients were classified according to their history of exacerbations before study entry, a similar demographic pattern was seen (Table S2); however, those reporting previous exacerbations were more likely to have a history of sputumproducing cough. Patients who experienced severe exacerbations showed poorer lung function, were more likely to be GOLD stage IV and group D, and had more breathlessness than frequent on-treatment exacerbators. In patients with fatal exacerbations, this pattern was even more pronounced (Table 1, Table S1).

\section{Baseline cardiovascular history and medication}

In general, there were no differences between the ontreatment and prestudy frequency groups in either their history of cardiovascular events or their use of cardiovascular medications (Table 1, Table S3). However, heart failure was present at study entry more often among those dying from an exacerbation.

\section{Baseline risk factors for exacerbation, hospitalization (due to COPD), and death (all-cause) \\ Risk of exacerbation}

Overall, univariate analysis identified the same baseline characteristics associated with differences in risk for exacerbation 


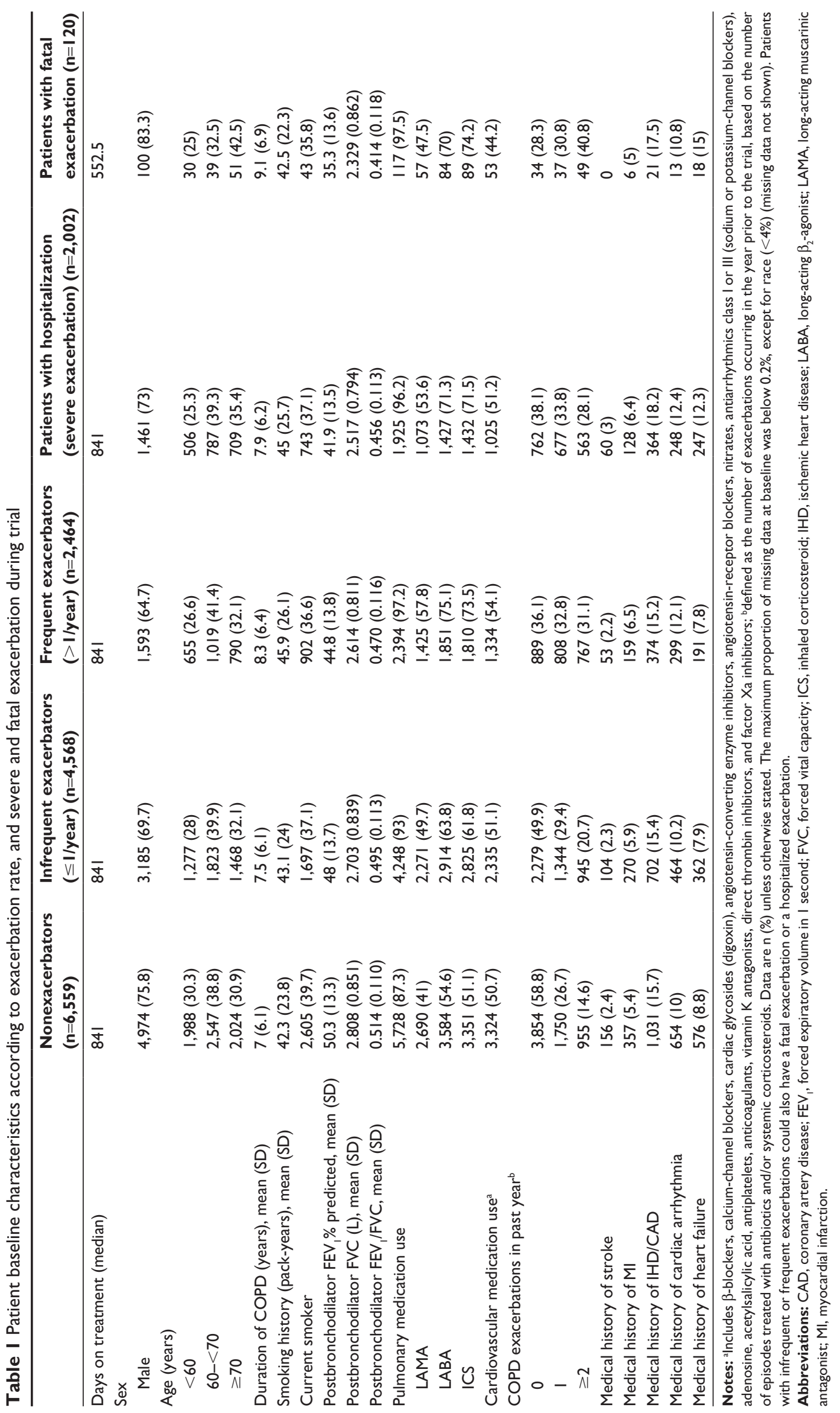




\section{Sex}

Female vs male

Age

$60-<70$ years vs $<60$ years

$\geq 70$ years $v s<60$ years

BMI

$\mathrm{BMI}<18.5$ vs $18.5 \leq \mathrm{BMI}<25$

$25 \leq \mathrm{BMl}<30$ vs $18.5 \leq \mathrm{BMl}<25$

$\mathrm{BMI} \geq 30$ vs $18.5 \leq \mathrm{BMI}<25$

Smoking status

Ex-smoker vs current smoker

Smoking history: $>40$ vs $\leq 40$ pack-years

Race

Black vs white

Asian vs white

Region

Latin America vs Euro/Africa/Aus/NZ

North America vs Euro/Africa/Aus/NZ

Asia vs Euro/Africa/Aus/NZ

Breathlessness (mMRC)

1 vs 0

2 vs 0

3 vs 0

4 vs 0

Sputum-producing cough

Yes vs no

Duration of COPD

$>6$ years vs $\leq 6$ years

Number of COPD episodes treated in the last year

1 vs none

2 vs none

3 vs none

4 vs none

$\geq 5$ vs none
GOLD stage

FEV $/$ /FVC $\geq 70 \%$ vs II

I vs II

III vs II

IV vs II

FVC-predicted GOLD stage-like classes

$50-<80 \% \geq 80 \%$

$30-<50 \%$ vs $\geq 80 \%$

$<30 \%$ vs $\geq 80 \%$

Baseline pulmonary medicine

ICS and LABA: yes vs no

LABA: yes vs no

Steroids (inhaled) yes vs no

Baseline cardiac medication

Yes vs no

Cardiac history

Yes vs no
A

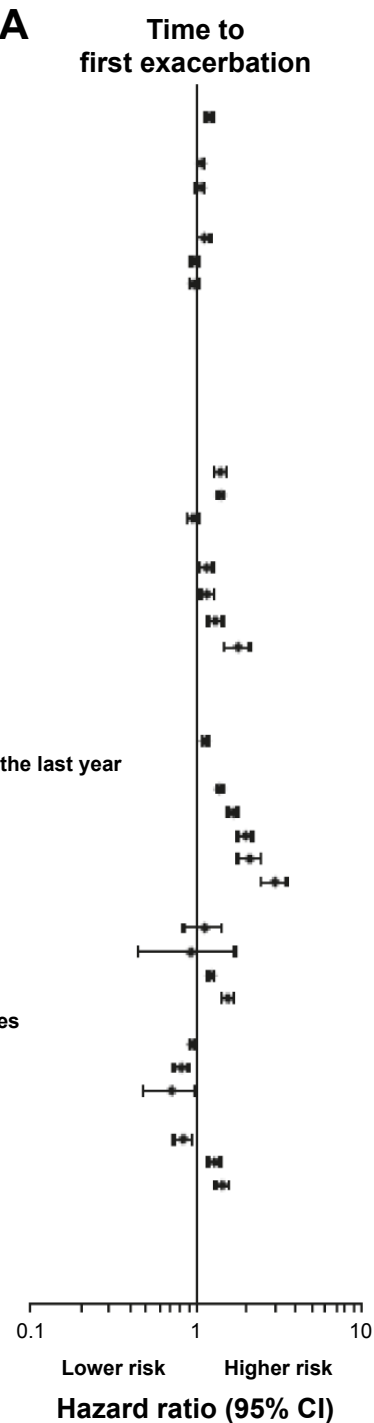

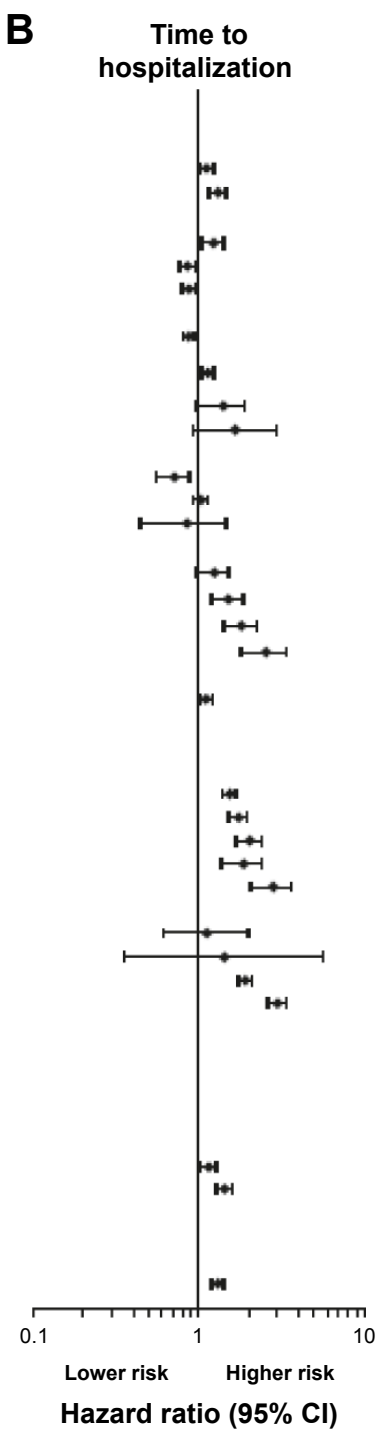

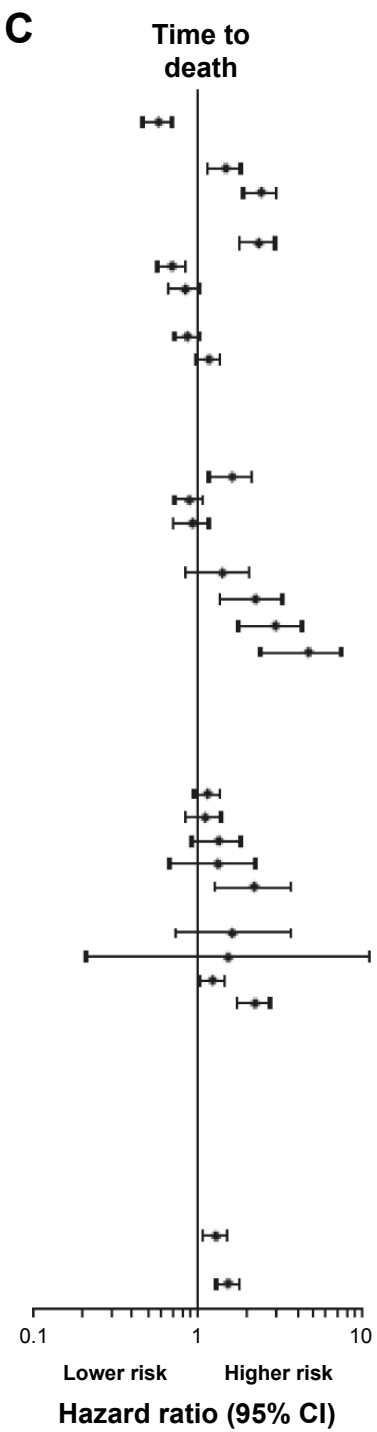

Figure I Multivariate Cox regression of time to (A) first exacerbation, (B) first hospitalization due to COPD exacerbation, and (C) death (treated set). Notes: Multivariate analyses performed separately for $\mathbf{A}, \mathbf{B}$, and $\mathbf{C}$, and not all variables qualified for all three analyses, hence not all variables included in final models. mMRC breathlessness descriptions: 0 , not troubled with breathlessness except with strenuous exercise; I, troubled by shortness of breath when hurrying on the level or walking up a slight hill; 2 , walks more slowly than people of the same age on the level because of breathlessness or has to stop for breath when walking at own pace on the level; 3 , stops for breath after walking about 100 yards [91.44 m] or after a few minutes on the level; 4 , too breathless to leave the house or breathless when dressing or undressing. Abbreviations: Aus, Australia; BMI, body-mass index; Euro, Europe; FEV ${ }_{1}$, forced expiratory volume in I second; FVC, forced vital capacity; ICS, inhaled corticosteroid; LABA, long-acting $\beta_{2}$-agonist; mMRC, modified Medical Research Council; NZ, New Zealand.

as the descriptive analysis (Figure S1A). Multivariate analysis adjusted for all other relevant covariates indicated that modified Medical Research Council scale breathlessness score, exacerbation history, airflow limitation $\left(\mathrm{FEV}_{1} \%\right.$ predicted), and LABA or ICS use at baseline (the surrogate marker for maintenance therapy) are the most important risk factors (Figure 1A).

Even after adjustment for all other important risk factors, baseline maintenance therapy with LABAs and ICSs remained relevant factors improving the model fit $(P<0.0001)$ (Table 2). The surrogate marker LAMA use could not be evaluated, as patients on LAMAs at baseline did not add an additional treatment during the study compared with those receiving LABAs or ICSs at baseline.

\section{Risk of hospitalization due to COPD}

Similar risk predictors as those for exacerbations were observed for hospitalization due to COPD, with the addition of poor FVC (Figure S1B). Multivariate analysis identified breathlessness score, exacerbation history, $\mathrm{FEV}_{1} \%$ predicted, ICS use at baseline (surrogate marker), and cardiac history as the most important factors; however, the analysis did not confirm the independent risk-modifying effect of FVC (Figure 1B). After adjustment for other risk 


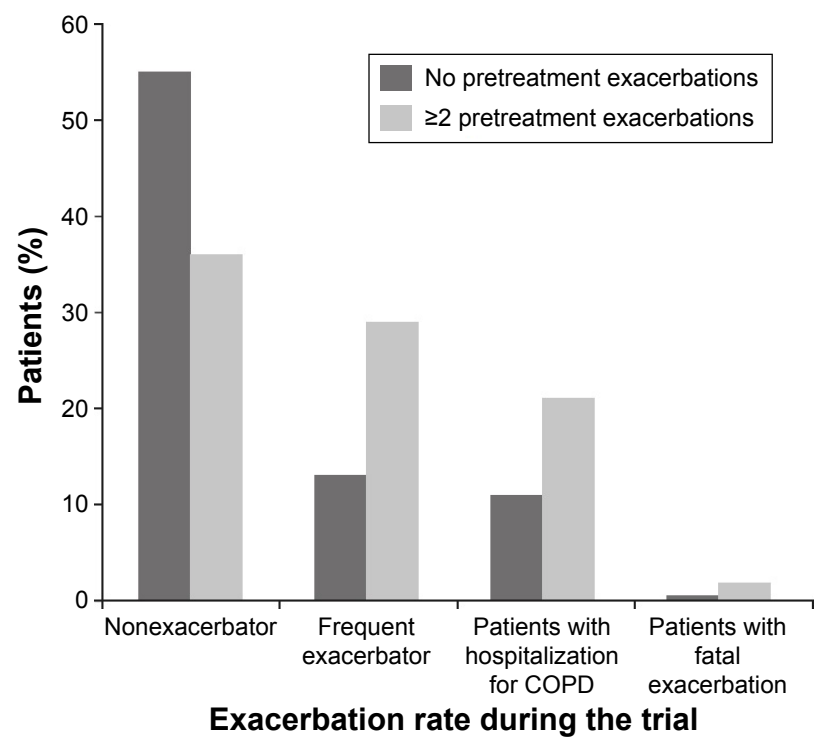

Figure 2 Exacerbation rate during the trial by pretreatment exacerbation history. Notes: In patients with $\geq 2$ years of follow-up or who died during the study. Patients with frequent exacerbations could also have a fatal exacerbation or a severe (hospitalized) exacerbation. Pretreatment exacerbations were defined as the number of exacerbations occurring in the year prior to the trial, based on the number of episodes treated with antibiotics and/or systemic corticosteroids.

factors, baseline maintenance therapy with LABAs and ICSs remained relevant factors for time to hospitalization due to COPD, improving the model fit $(P<0.0001)$ (Table 2).

\section{Risk of death (all-cause)}

With respect to mortality, significant predictors included sex, age, BMI, breathlessness score, exacerbation history, lung function $\left(\mathrm{FEV}_{1} \%\right.$ predicted and $\left.\mathrm{FVC}\right)$, and history of

Table 2 Likelihood-ratio test for baseline maintenance therapies

\begin{tabular}{llll}
\hline Endpoint & df & $\chi^{2}$ & P-value \\
\hline $\begin{array}{l}\text { Time to first exacerbation } \\
\quad \text { LABA use at baseline }\end{array}$ & I & 234.7 & $<0.000$ I \\
$\quad$ ICS use at baseline & I & 259.74 & $<0.000$ I \\
Time to hospitalization due to COPD & & & \\
$\quad$ LABA use at baseline & I & 67.74 & $<0.000$ I \\
ICS use at baseline & I & 91.66 & $<0.000$ I \\
Time to death & & & \\
$\quad$ LABA use at baseline & I & 0.0003 & 0.9867 \\
ICS use at baseline & I & 0.0478 & 0.8269 \\
\hline
\end{tabular}

Notes: alncludes sex, age, body-mass index, region, duration of COPD (years), COPD episodes treated in last year, GOLD stage, FVC-predicted GOLD stage-like class (ECSC, Caucasian), cardiac history, and mMRC scale; bincludes age, body-mass index, smoking status, smoking history (pack-years), race, region, sputum-producing cough, COPD episodes treated in last year, GOLD stage, cardiac history, and mMRC scale; cincludes sex, age, body-mass index, smoking status, smoking history (pack-years), region, COPD episodes treated in last year, GOLD stage, baseline cardiac medication, cardiac history, and $\mathrm{mMRC}$ scale.

Abbreviations: ECSC, European Community for Coal and Steel; FVC, forced vital capacity; ICS, inhaled corticosteroid; LABA, long-acting $\beta_{2}$-agonist; mMRC, modified Medical Research Council. cardiac events (Figure S1C). With the exception of FVC, these factors were confirmed by multivariate analysis, indicating that underweight male patients were at increased risk of dying, and this risk increased with age, reduced lung function, and exacerbation frequency.

\section{Effect of exacerbation history and baseline pulmonary therapy on exacerbation, hospitalization, and death} Risk of exacerbation

When analyzing the risk-modifying effect of exacerbation history and baseline LABA/ICS use on exacerbation (analysis adjusted for smoking status and postbronchodilator $\mathrm{FEV}_{1}$ at baseline), patients with a history of frequent exacerbations (annual exacerbation rate $>1$ ) were at significantly higher risk of exacerbations during the trial. This higher risk of exacerbations for frequent exacerbators was irrespective of their LABA or ICS use at baseline $(P<0.0001)$ versus nonexacerbators (Table 3A). Nevertheless, use of ICSs at baseline was a marker for increased risk of further exacerbations in patients with and without exacerbation history. Overall, patients receiving ICS or LABA therapy did not show a lower exacerbation risk than patients without ICS or LABA use at baseline (Table 3A). Kaplan-Meier analysis of time to first exacerbation showed that patients without an exacerbation history who used ICSs at baseline had a similar risk of exacerbation as patients with previous exacerbations without ICS use (Figure 3A).

\section{Risk of hospitalization due to COPD}

Kaplan-Meier analysis of time to hospitalization showed that the ICS-use marker and a history of more than one exacerbation were associated with increased risk of hospitalization (Figure 3B).

\section{Risk of death (all-cause)}

Patients receiving ICSs/LABAs at baseline were not at an increased risk of mortality during the trial compared with patients not receiving the combination, irrespective of exacerbation history (Table 3B). Similarly, patients receiving ICSs or LABAs did not have a lower risk of mortality compared with patients not receiving ICSs or LABAs, respectively (Table 3B). Patients with an exacerbation history receiving ICSs plus LABAs were, however, at an increased risk of mortality compared with those without a history of exacerbations. Therefore, past exacerbations warranting ICS/LABA use are an indicator for increased risk of death (Table 3B). Kaplan-Meier analysis of time to death showed that ICS use 


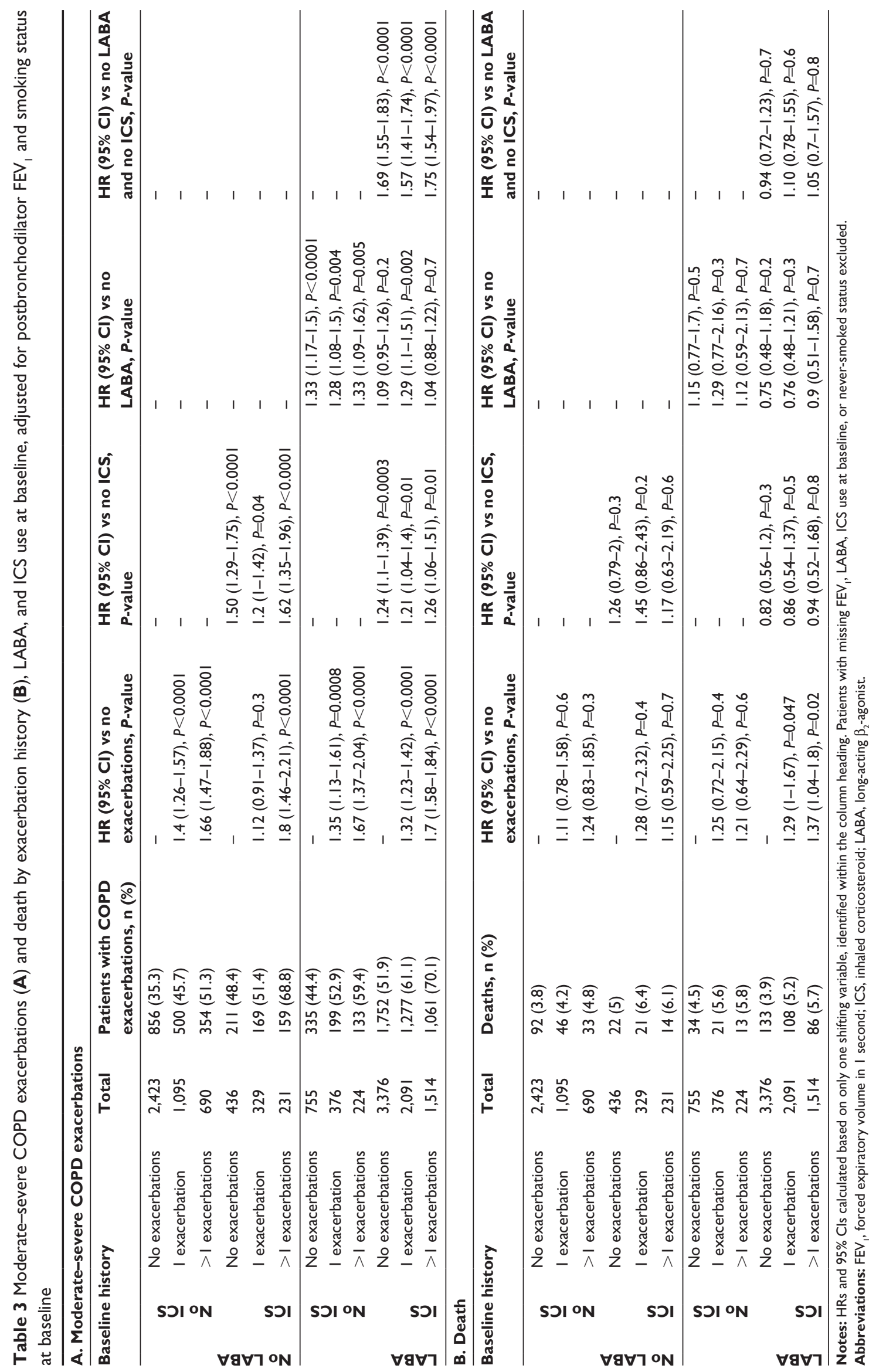


and a history of more than one exacerbation were associated with increased risk of death (Figure 3C).

\section{Stability of exacerbation phenotype}

In the first year, 11,885 patients were infrequent exacerbators ( $0-1$ exacerbation). Of these, $10,953(92.2 \%)$ were also infrequent exacerbators in the second year. However, of the 1,706 patients with two or more exacerbations in the first year (frequent exacerbators), 1,023 (60\%) were infrequent exacerbators in the second year.

\section{Discussion}

Identifying patients at greatest risk of exacerbation should facilitate the clinical management of COPD. In this large population of patients who were initially clinically stable and whose therapy always included the LAMA tiotropium, we found a similar risk profile to that reported in other groups where therapy was less standardized. Important factors included history of prior exacerbations, more dyspnea, poor lung function, and female sex. Medication use at baseline represented an independent risk of future exacerbation, but was not as important as exacerbation history in identifying those at risk of hospitalization or death. These data have implications for how we evaluate COPD patients already receiving treatment.

Unlike earlier studies, TIOSPIR participants all received a LAMA via either HandiHaler or Respimat, but in addition could continue with any non-LAMA therapy. The resulting population would be one that would occur if the health-care provider followed recommendations for treatment of current GOLD groups B-D. ${ }^{16}$ Standardizing therapy in this way did not change the relative contribution of predictive factors associated with exacerbations.

There was no difference in age, smoking status, or BMI category between individuals with frequent events and those who never experienced an exacerbation over the $\geq 2$ years of follow-up. As in the ECLIPSE study, ${ }^{5}$ a history of sputumproducing cough in our patients did not predict those more likely to exacerbate. This difference from the data reported in COPDGene participants ${ }^{17}$ and other studies ${ }^{18}$ may reflect differences in the definition of chronic bronchitis that is used: studies that did not use the classic definition of chronic bronchitis were more likely to identify an association between chronic cough and exacerbation frequency. ${ }^{19,20}$ Neither a history of cardiac disease nor cardiac medication use distinguished the exacerbation groups (grouped by exacerbation frequency and severe and fatal exacerbation), suggesting that in this population most events were driven by respiratory rather than cardiac causes. As in earlier reports, both postbronchodilator $\mathrm{FEV}_{1}$ and dyspnea intensity were related to exacerbation frequency. However, there was considerable overlap between subgroups, with a third of frequent exacerbators having a modified Medical Research Council grade $\leq 1$ at baseline.

When the effect of relevant covariates (postbronchodilator $\mathrm{FEV}_{1}$ and smoking status at baseline) was controlled for, the same relationships for exacerbation frequency and time to first exacerbation held true; this was also the case for time to hospitalization and death. Sex was an exception, where females were more likely to experience exacerbations, but less likely to die. This paradoxical finding has been noted previously, and no satisfactory explanation currently exists for this anomaly. ${ }^{21}$ However, it has been suggested that women are more often underdiagnosed, show lower adherence to treatment than men, and present with fewer comorbidities. ${ }^{22}$

A history of exacerbations (in the year before the study) was a powerful explanatory variable, with evidence of a dose-response effect for time to first exacerbation and time to hospitalization, although less evident for time to death. However, the use of exacerbation history as a categorical variable in individual patients as proposed by GOLD (" 0 or 1 indicates low risk, while 2 or more exacerbations indicate high risk") was rather disappointing. ${ }^{16}$ Overall, 55\% of patients remained exacerbation-free if they had no exacerbation in the year before the study, while $45 \%$ did not, despite all of them using at least a LAMA. Additionally, $13 \%$ of patients without exacerbation history became frequent exacerbators, and $36 \%$ of frequent exacerbators before the study had no exacerbations during the study.

ECLIPSE noted that patients did shift from high-risk to low-risk exacerbator groups over time, and the reasons for doing so were unclear. ${ }^{23}$ Recently, Han et al made similar observations regarding the instability of the frequent-exacerbator phenotype in the SPIROMICS cohort. ${ }^{24}$ However, adequate therapy seems to improve the ratio of infrequent to frequent exacerbators over time. ${ }^{25-27}$ Our data emphasize that patients with COPD have the propensity to exacerbate during the course of their disease, and that prior exacerbation history is only an approximate guide as to what will happen subsequently, not a precise predictor of exacerbation risk. As all our patients received the same COPD maintenance therapy on treatment, other factors may also be relevant for changes in risk over time.

The use of a maintenance respiratory therapy, such as a LABA, LAMA, or ICS, is usually considered in terms of the ability of that treatment to prevent exacerbations, rather than as a marker of the likelihood that they will occur. However, 
A

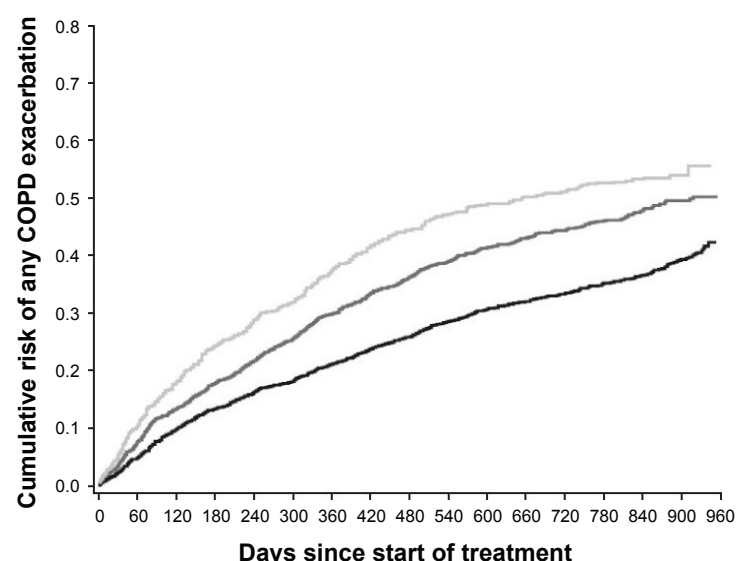

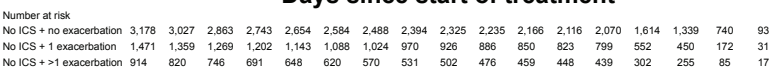

B

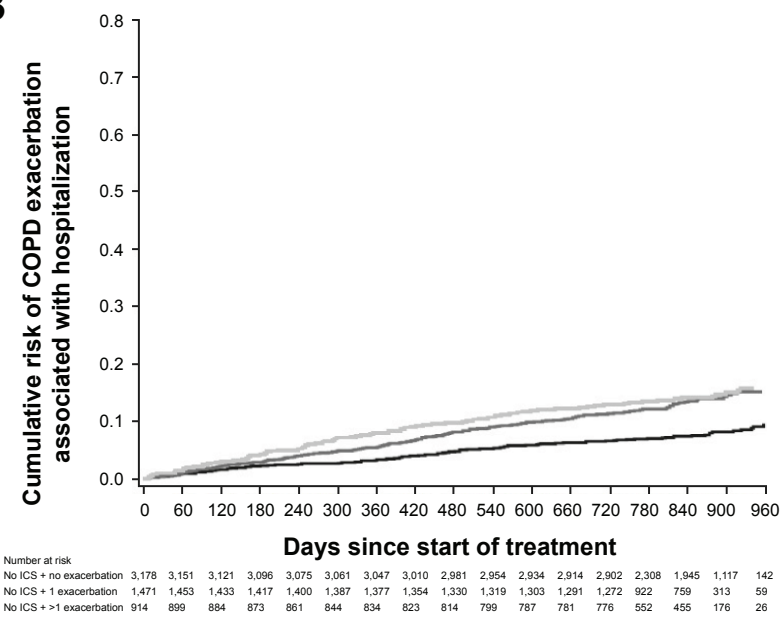

C

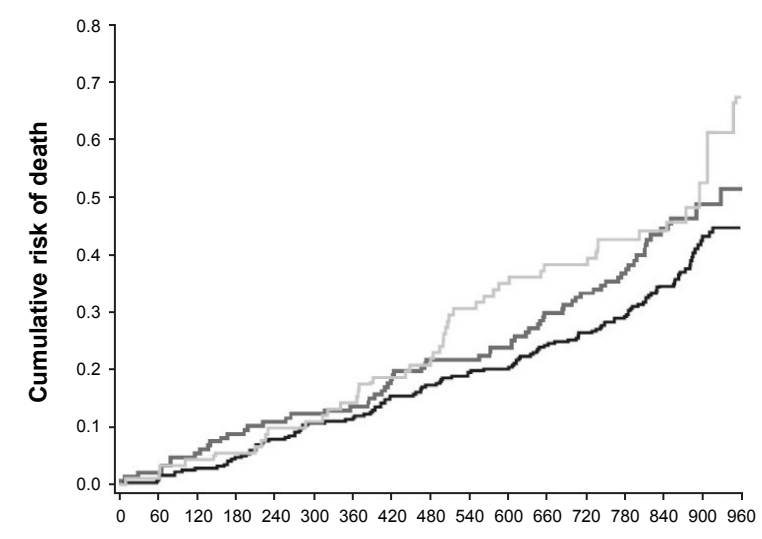

Days since start of treatment

Number a ti isk
No ICS no no

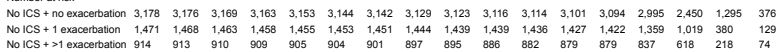

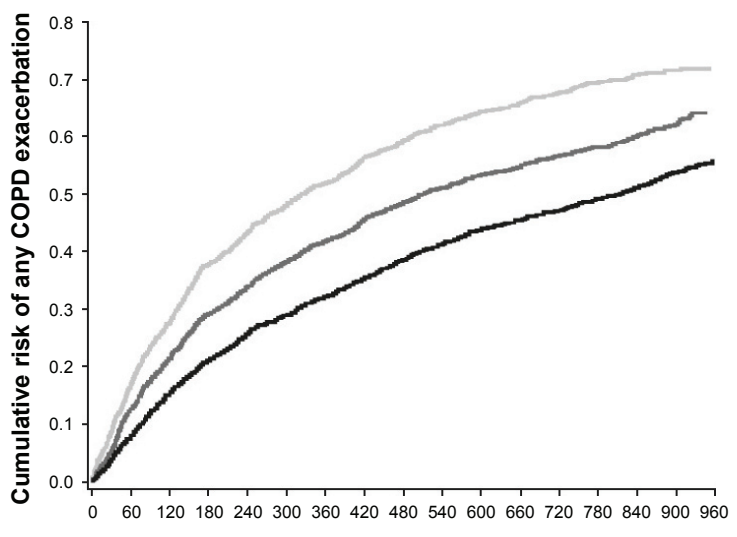

Days since start of treatment
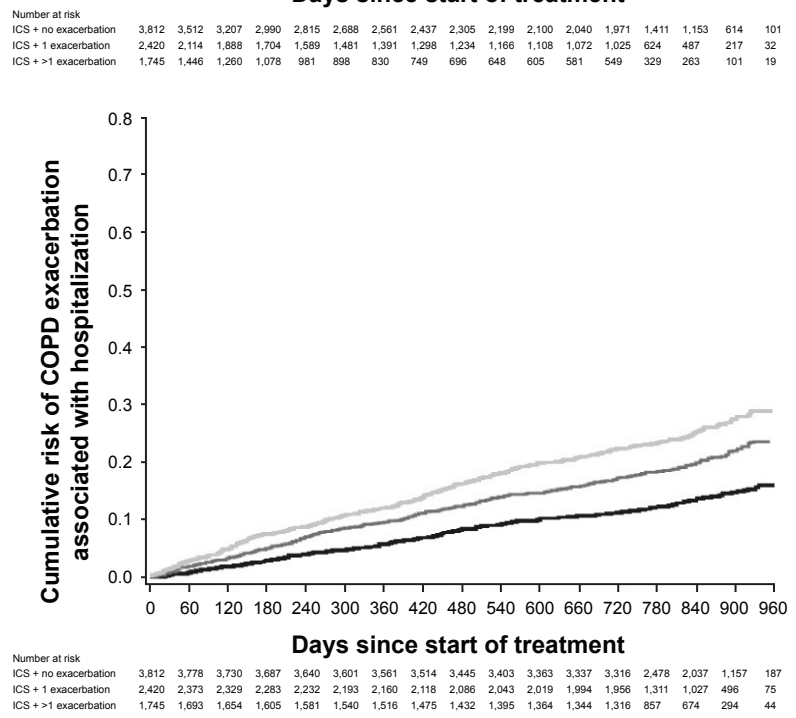

Number at risk

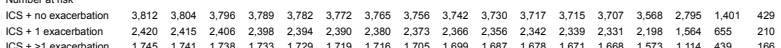

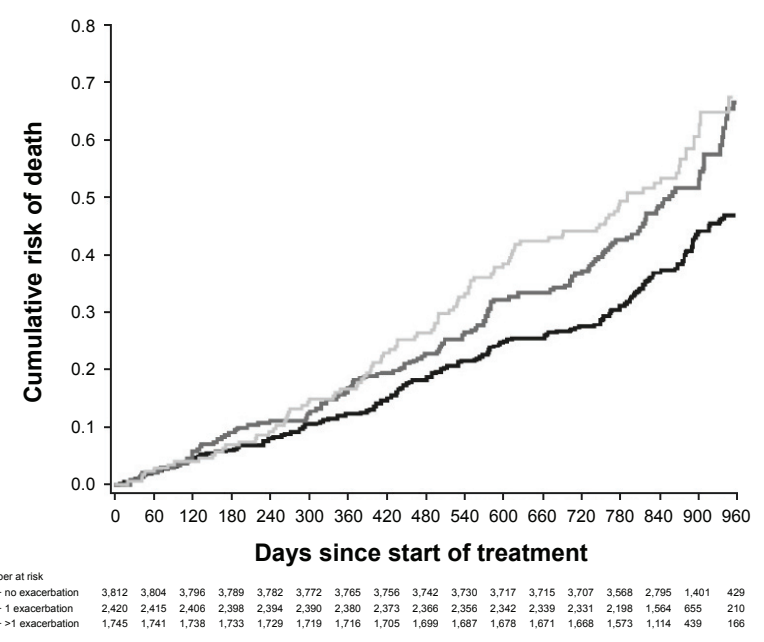

Subgroup
No ICS + no exacerbation $ـ$ No ICS +1 exacerbation $—$ No ICS $+>1$ exacerbation

Subgroup
$\longrightarrow$ ICS + no exacerbation - ICS +1 exacerbation - ICS $+>1$ exacerbation

Figure 3 Time to first exacerbation $(\mathbf{A})$, hospitalization $(\mathbf{B})$ or death $(\mathbf{C})$ according to exacerbation rate in the year preceding the trial and ICS use at baseline. Abbreviation: ICS, inhaled corticosteroids.

prior use of certain treatments, especially ICSs, which are almost exclusively prescribed as a way to prevent exacerbations, has been shown to identify patients more likely to exacerbate, ${ }^{28}$ a finding supported by clinical trial data where prior ICS users had a higher exacerbation rate postrandomization..$^{29}$ Our data suggest that both LABA and ICS use predicts a higher rate of subsequent exacerbations, and that this is true irrespective of the previous exacerbation rate. Nevertheless, 
this only applied to the risk of a health-care utilizationdefined exacerbation. This relationship might mean that therapy increased the risk of exacerbations, although this is unlikely given the wealth of randomized controlled data suggesting the opposite. ${ }^{30,31}$ A more likely explanation is that patients are given these drugs to prevent exacerbations and/or because they are believed to be progressing less well, and thus are more likely to relapse in future, irrespective of any positive effect of their therapy. Hospitalizations and death were related to exacerbation history, but not medication use.

Our study has strengths and limitations. Although not as large as the recent UK database study, ${ }^{28}$ exacerbations were prospectively defined and collected. We considered data over a potential 2-year follow-up period in a substantial number of patients, and had a near-complete assessment of vital status. The universal use of LAMA therapy allowed us to not just assess how this treatment option related to exacerbation outcomes but also how the use of other treatments interacted with LAMA use. However, these treatments were not randomized and reflected the treatment choices of clinicians. We did not evaluate the surrogate marker LAMA use at baseline. Patients on LAMAs prior to the study simply remained on them, unlike patients receiving LABAs or ICSs at baseline, who had a LAMA added to their therapy. This analysis would thus show the benefit of adding a LAMA, rather than the risk of being on a LAMA. In addition, biomarker data were not included, which some have suggested are associated with more events, ${ }^{32}$ although these are not routinely recorded. Furthermore, when describing associations between current treatment and future risk, there is the limitation that the characteristics of patients at the time of prescription are not known, nor is the effect of the treatments on these characteristics.

Our data have some clinical implications. The similarity of the risk profile in our patients to those reported in groups where treatment was less rigidly controlled not only supports attempts to predict the inherent likelihood of exacerbation, ${ }^{33}$ but also supports the idea of an "exacerbator phenotype" and its use as a way to stratify future risk. However, reliance on exacerbation history alone can be misleading, and factors other than those commonly assessed, and specifically prior and/or current therapy, should be considered when assessing the likelihood of the individual patient experiencing future exacerbations. The additional role of treatment as a marker of the propensity to exacerbate resembles the situation in asthma, where treatment steps are commonly linked to the therapy already prescribed. Whether a similar system can be developed for COPD patients will be for others to determine.

\section{Acknowledgments}

This study was funded by Boehringer Ingelheim. Writing assistance was provided by Sarah J Petit and Jennifer C Fuchs of Parexel and Kristina Standeven of MediTech Media, and was funded by Boehringer Ingelheim.

\section{Author contributions}

All authors contributed toward data analysis, drafting and revising the paper and agree to be accountable for all aspects of the work.

\section{Disclosure}

PMAC reports receiving consulting fees, lecture fees, and travel support from Novartis, GlaxoSmithKline, Boehringer Ingelheim, and Takeda. DD reports receiving consulting fees, lecture fees, and payment for the development of educational activities from Boehringer Ingelheim, Pfizer, Novartis, Chiesi, Nycomed, and Dey Pharma. RAW reports receiving consulting fees from AstraZeneca, Boehringer Ingelheim, Bristol-Myers Squibb, ContraFect, GlaxoSmithKline, Janssen, Mylan, Novartis, Pfizer, Pulmonx, Roche, Spiration, Sunovion, Teva, Theravance, Verona, and Vertex, and grant support from Boehringer Ingelheim, GlaxoSmithKline, and Pearl Therapeutics. KT, AM, and NM are employees of Boehringer Ingelheim, and ARA reports receiving consulting fees, lecture fees, and travel support from AstraZeneca, Boehringer Ingelheim, Forest Laboratories, GlaxoSmithKline, and Novartis and grant support from GlaxoSmithKline. The authors report no other conflicts of interest in this work.

\section{References}

1. Vestbo J, Edwards LD, Scanlon PD, et al. Changes in forced expiratory volume in 1 second over time in COPD. N Engl J Med. 2011;365(13): $1184-1192$.

2. Wilke S, Jones PW, Müllerova $\mathrm{H}$, et al. One-year change in health status and subsequent outcomes in COPD. Thorax. 2015;70(5):420-425.

3. Müllerova H, Maselli DJ, Locantore N, et al. Hospitalized exacerbations of COPD: risk factors and outcomes in the ECLIPSE cohort. Chest. 2015;147(4):999-1007.

4. Beeh KM, Glaab T, Stowasser S, et al. Characterisation of exacerbation risk and exacerbator phenotypes in the POET-COPD trial. Respir Res. 2013;14:116.

5. Hurst JR, Vestbo J, Anzueto A, et al. Susceptibility to exacerbation in chronic obstructive pulmonary disease. $N$ Engl J Med. 2010;363(12): $1128-1138$.

6. Kim V, Criner GJ. Chronic bronchitis and chronic obstructive pulmonary disease. Am J Respir Crit Care Med. 2013;187(3):228-237.

7. De Soyza A, Calverley PM. Large trials, new knowledge: the changing face of COPD management. Eur Respir J. 2015;45(6):1692-1703.

8. Vestbo J, Agusti A, Wouters EF, et al. Should we view chronic obstructive pulmonary disease differently after ECLIPSE? A clinical perspective from the study team. Am J Respir Crit Care Med. 2014;189(9): $1022-1030$. 
9. Farne HA, Cates CJ. Long-acting beta ${ }_{2}$-agonist in addition to tiotropium versus either tiotropium or long-acting beta $_{2}$-agonist alone for chronic obstructive pulmonary disease. Cochrane Database Syst Rev. 2015;(10):CD008989.

10. Decramer ML, Chapman KR, Dahl R, et al. Once-daily indacaterol versus tiotropium for patients with severe chronic obstructive pulmonary disease (INVIGORATE): a randomised, blinded, parallel-group study. Lancet Respir Med. 2013;1(7):524-533.

11. Vogelmeier C, Hederer B, Glaab T, et al. Tiotropium versus salmeterol for the prevention of exacerbations of COPD. N Engl J Med. 2011; 364(12):1093-1103.

12. Global Initiative for Asthma. 2016 GINA Report: Global Strategy for Asthma Management and Prevention. Bethesda (MD): GINA; 2016.

13. Wise RA, Anzueto A, Calverley P, et al. The Tiotropium Safety and Performance in Respimat Trial (TIOSPIR), a large scale, randomized, controlled, parallel-group trial-design and rationale. Respir Res. 2013;14:40.

14. Wise RA, Anzueto A, Cotton D, et al. Tiotropium Respimat inhaler and the risk of death in COPD. N Engl J Med. 2013;369(16):1491-1501.

15. Vestbo J, Hurd SS, Rodriguez-Roisin R. The 2011 revision of the global strategy for the diagnosis, management and prevention of COPD (GOLD): why and what? Clin Respir J. 2012;6(4):208-214.

16. Global Initiative for Chronic Obstructive Lung Disease. Global Strategy for Diagnosis, Management, and Prevention of Chronic Obstructive Pulmonary Disease. Bethesda (MD): GOLD; 2016.

17. Busch R, Han MK, Bowler RP, et al. Risk factors for COPD exacerbations in inhaled medication users: the COPDGene study biannual longitudinal follow-up prospective cohort. BMC Pulm Med. 2016;16:28.

18. Burgel PR. Chronic cough and sputum production: a clinical COPD phenotype? Eur Respir J. 2012;40(1):4-6.

19. Kim V, Sternberg AL, Washko G, et al. Severe chronic bronchitis in advanced emphysema increases mortality and hospitalizations. COPD. 2013;10(6):667-678.

20. Kim V, Crapo J, Zhao H, et al. Comparison between an alternative and the classic definition of chronic bronchitis in COPDGene. Ann Am Thorac Soc. 2015;12(3):332-339.

21. Celli B, Vestbo J, Jenkins CR, et al. Sex differences in mortality and clinical expressions of patients with chronic obstructive pulmonary disease: the TORCH experience. Am JRespir Crit Care Med.2011;183(3): $317-322$.
22. Kilic H, Kokturk N, Sari G, Cakir M. Do females behave differently in COPD exacerbation? Int J Chron Obstruct Pulmon Dis. 2015; 10:823-830.

23. Donaldson GC, Müllerova H, Locantore N, et al. Factors associated with change in exacerbation frequency in COPD. Respir Res. 2013;14:79.

24. Han MK, Quibrera PM, Carretta EE, et al. Frequency of exacerbations in patients with chronic obstructive pulmonary disease: an analysis of the SPIROMICS cohort. Lancet Respir Med. 2017;5(8):619-626.

25. Celli BR, Decramer M, Asijee GM, Kupas K, Tashkin DP. Effects of tiotropium on exacerbations in patients with COPD with low or high risk of exacerbations: a post-hoc analysis from the 4-year UPLIFT trial. Chronic Obstr Pulm Dis. 2015;2(2):122-130.

26. Vogelmeier CF, Asijee GM, Kupas K, Beeh KM. Tiotropium and salmeterol in COPD patients at risk of exacerbations: a post hoc analysis from POET-COPD. Adv Ther. 2015;32(6):537-547.

27. Wedzicha JA, Rabe KF, Martinez FJ, et al. Efficacy of roflumilast in the COPD frequent exacerbator phenotype. Chest. 2013;143(5): 1302-1311.

28. Müllerova H, Shukla A, Hawkins A, Quint J. Risk factors for acute exacerbations of COPD in a primary care population: a retrospective observational cohort study. BMJ Open. 2014;4(12):e006171.

29. Bateman ED, Rabe KF, Calverley PM, et al. Roflumilast with longacting $\beta_{2}$-agonists for COPD: influence of exacerbation history. Eur Respir J. 2011;38(3):553-560.

30. Calverley PM, Anderson JA, Celli B, et al. Salmeterol and fluticasone propionate and survival in chronic obstructive pulmonary disease. N Engl J Med. 2007;356(8):775-789.

31. Celli B, Decramer M, Kesten S, et al. Mortality in the 4-year trial of tiotropium (UPLIFT) in patients with chronic obstructive pulmonary disease. Am J Respir Crit Care Med. 2009;180(10):948-955.

32. Thomsen M, Ingebrigtsen TS, Marott JL, et al. Inflammatory biomarkers and exacerbations in chronic obstructive pulmonary disease. JAMA. 2013;309(22):2353-2361.

33. Make BJ, Eriksson G, Calverley PM, et al. A score to predict short-term risk of COPD exacerbations (SCOPEX). Int J Chron Obstruct Pulmon Dis. 2015;10:201-209. 


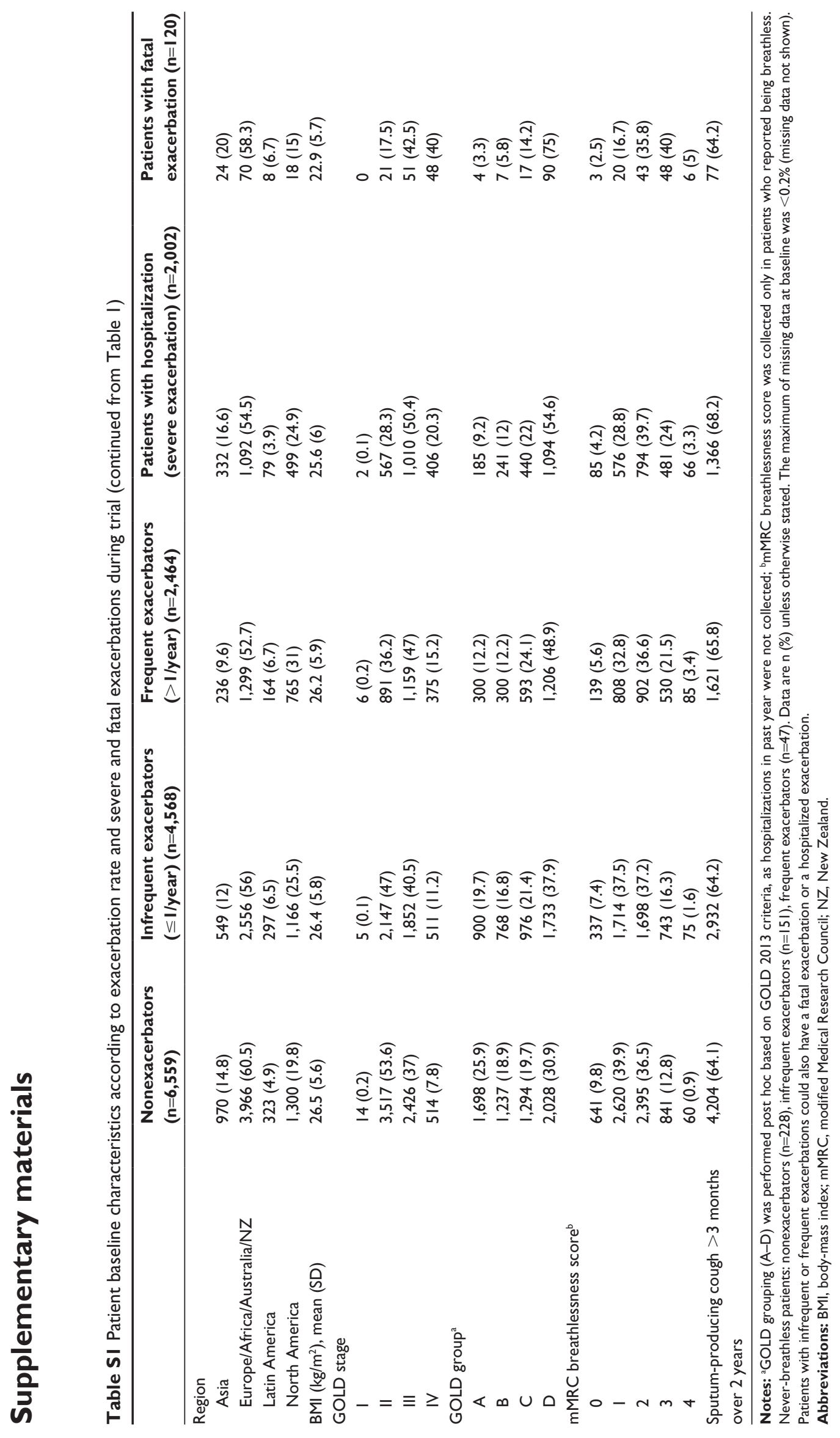


Table S2 Patient baseline characteristics according to the number of exacerbations in the year preceding the trial

\begin{tabular}{|c|c|c|c|}
\hline Baseline characteristics & $\begin{array}{l}\text { No exacerbation in year } \\
\text { prior to study }(n=7,022)\end{array}$ & $\begin{array}{l}\text { One exacerbation in year } \\
\text { prior to study }(n=3,902)\end{array}$ & $\begin{array}{l}\text { More than one exacerbation in } \\
\text { year prior to study }(n=2,667)\end{array}$ \\
\hline Days on treatment (median) & 842 & 840 & 840 \\
\hline \multicolumn{4}{|l|}{ Sex } \\
\hline Male & $5,073(72.2)$ & 2,79I (7I.5) & $\mathrm{I}, 888(70.8)$ \\
\hline \multicolumn{4}{|l|}{ Region } \\
\hline Asia & $866(12.3)$ & $515(13.2)$ & $374(14)$ \\
\hline Europe/Africa/Australia/NZ & $3,692(52.6)$ & $2,394(61.4)$ & $1,735(65.1)$ \\
\hline Latin America & $305(4.3)$ & $306(7.8)$ & $173(6.5)$ \\
\hline North America & $2,159(30.7)$ & $687(17.6)$ & $385(14.4)$ \\
\hline \multicolumn{4}{|l|}{ Age (years) } \\
\hline$<60$ & $1,918(27.3)$ & $\mathrm{I}, 152(29.5)$ & $850(31.9)$ \\
\hline $60-<70$ & $2,832(40.3)$ & $1,547(39.6)$ & $1,010(37.9)$ \\
\hline$\geq 70$ & $2,272(32.4)$ & I,203 (30.8) & $807(30.3)$ \\
\hline BMI $\left(\mathrm{kg} / \mathrm{m}^{2}\right)$, mean $(\mathrm{SD})$ & $26.6(5.7)$ & $26.2(5.6)$ & $26.2(5.6)$ \\
\hline Duration of COPD (years), mean (SD) & $6.9(5.9)$ & $7.3(6)$ & $8.7(6.7)$ \\
\hline Smoking history (pack-years), median & 40 & 40 & 36 \\
\hline Current smoker & $2,77 \mid(39.5)$ & $\mathrm{I}, 43 \mathrm{I}(36.7)$ & $1,002(37.6)$ \\
\hline Postbronchodilator $\mathrm{FEV}, \%$ predicted, mean (SD) & $49.8(13.5)$ & $47.8(13.5)$ & $46.2(14.2)$ \\
\hline Postbronchodilator FVC (L), mean (SD) & $2.798(0.85)$ & $2.692(0.827)$ & $2.644(0.836)$ \\
\hline Postbronchodilator $\mathrm{FEV}_{1} / \mathrm{FVC}$, mean (SD) & $0.505(0.1 \mathrm{II})$ & $0.499(0.114)$ & $0.489(0.119)$ \\
\hline \multicolumn{4}{|l|}{ GOLD stage } \\
\hline I & $16(0.2)$ & $3(0.1)$ & $6(0.2)$ \\
\hline II & $3,646(51.9)$ & $\mathrm{I}, 785(45.7)$ & $\mathrm{I}, 124(42.1)$ \\
\hline III & $2,647(37.7)$ & $\mathrm{I}, 668(42.7)$ & $1,122(42.1)$ \\
\hline IV & $612(8.7)$ & $410(10.5)$ & $378(14.2)$ \\
\hline \multicolumn{4}{|l|}{ GOLD group ${ }^{\mathrm{a}}$} \\
\hline A & $2,042(29.1)$ & $856(21.9)$ & 0 \\
\hline B & $\mathrm{I}, 425(20.3)$ & $880(22.6)$ & 0 \\
\hline C & $1,298(18.5)$ & $697(17.9)$ & $868(32.5)$ \\
\hline $\mathrm{D}$ & $1,856(26.4)$ & $\mathrm{I}, 35 \mathrm{I}(34.6)$ & $1,760(66)$ \\
\hline Pulmonary medication use & $6,291(89.6)$ & $3,626(92.9)$ & $2,453(92)$ \\
\hline LAMA & $3,426(48.8)$ & $\mathrm{I}, 773(45.4)$ & $\mathrm{I}, 187(44.5)$ \\
\hline LABA & $4,139(58.9)$ & $2,468(63.2)$ & $1,742(65.3)$ \\
\hline ICS & $3,816(54.3)$ & $2,42 I(62)$ & $1,749(65.6)$ \\
\hline CV-medication ${ }^{\mathrm{b}}$ use & $3,65 \mathrm{I}(52)$ & $2,010(51.5)$ & $1,332(49.9)$ \\
\hline \multicolumn{4}{|l|}{ mMRC breathlessness score } \\
\hline 0 & $792(11.3)$ & $229(5.9)$ & $96(3.6)$ \\
\hline 1 & $2,906(41.4)$ & $\mathrm{I}, 425(36.5)$ & $811(30.4)$ \\
\hline 2 & $2,303(32.8)$ & $1,570(40.2)$ & $1,122(42.1)$ \\
\hline 3 & $921(13.1)$ & $615(15.8)$ & $578(21.7)$ \\
\hline 4 & $99(1.4)$ & $61(1.6)$ & $60(2.2)$ \\
\hline Sputum-producing cough $>3$ months over 2 years & $3,964(56.5)$ & $2,743(70.3)$ & $2,050(76.9)$ \\
\hline Medical history of stroke & $176(2.5)$ & $81(2.1)$ & $56(2.1)$ \\
\hline Medical history of MI & $444(6.3)$ & $198(5.1)$ & $144(5.4)$ \\
\hline Medical history of IHD/CAD & $987(14.1)$ & $632(16.2)$ & $488(18.3)$ \\
\hline Medical history of cardiac arrhythmia & $722(10.3)$ & $418(10.7)$ & $277(10.4)$ \\
\hline Medical history of heart failure & $399(5.7)$ & $389(10)$ & $341(12.8)$ \\
\hline
\end{tabular}

Notes: aGOLD grouping (A-D) was performed post hoc based on GOLD 2013 criteria, as hospitalizations in past year were not collected; bincludes $\beta$-blockers, calciumchannel blockers, cardiac glycosides (digoxin), angiotensin-converting enzyme inhibitors, angiotensin-receptor blockers, nitrates, antiarrhythmics class I or III (sodium- or potassium-channel blockers), adenosine, acetylsalicylic acid, antiplatelets, anticoagulants, vitamin $\mathrm{K}$ antagonists, direct thrombin inhibitors, and factor $\mathrm{Xa}$ inhibitors. Data are $\mathrm{n}(\%)$ unless otherwise stated. The maximum proportion of missing data at baseline was below $0.2 \%$, except for race $(<4 \%)$ (missing data not shown).

Abbreviations: BMI, body-mass index; CAD, coronary artery disease; CV, cardiovascular; FEV , forced expiratory volume in I second; FVC, forced vital capacity; ICS, inhaled corticosteroid; IHD, ischemic heart disease; LABA, long-acting $\beta_{2}$-agonist; LAMA, long-acting muscarinic antagonist; MI, myocardial infarction; mMRC, modified Medical Research Council; NZ, New Zealand. 


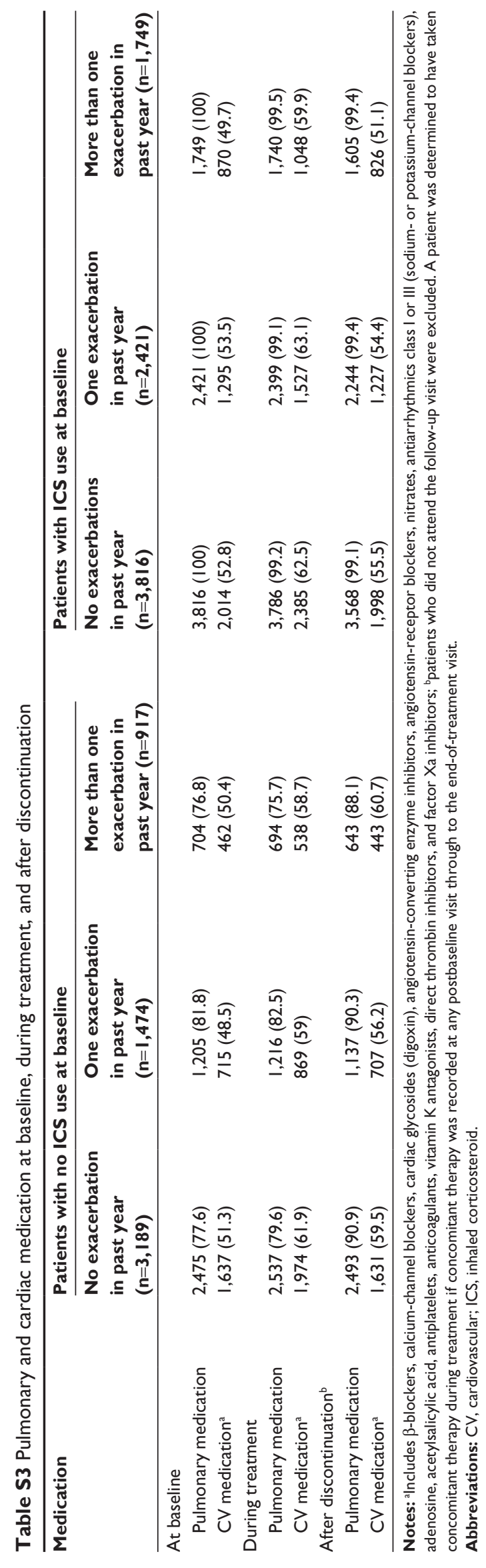


Sex

Female vs male

Age

$60-<70$ years vs $<60$ years

$\geq 70$ years $v s<60$ years

BMI

$\mathrm{BMI}<18.5$ vs $18.5 \leq \mathrm{BMI}<25$

$25 \leq \mathrm{BMI}<30$ vs $18.5 \leq \mathrm{BMI}<25$

$\mathrm{BMI} \geq 30$ vs $18.5 \leq \mathrm{BMI}<25$

Smoking status

Ex-smoker vs current smoker

Smoking history: $>40$ vs $\leq 40$ pack-years

\section{Race}

Black vs white

Asian vs white

Region

Latin America vs Euro/Africa/Aus/NZ

North America vs Euro/Africa/Aus/NZ

Asia vs Euro/Africa/Aus/NZ

Breathlessness (mMRC)

1 vs 0

2 vs 0

3 vs 0

4 vs 0

Sputum-producing cough

Yes vs no

Duration of COPD

$>6$ years vs $\leq 6$ years

Number of COPD episodes treated in the last year

1 vs none

2 vs none

3 vs none

4 vs none

$\geq 5$ vs none

$\geq 2$ exacerbations in the last year

Yes vs no

GOLD stage

$\mathrm{FEV}_{1} / \mathrm{FVC} \geq 70 \%$ vs II

I vs II

III vs II

IV vs II

FVC-predicted GOLD stage-like classes

$50-<80 \% \geq 80 \%$

$30-<50 \%$ vs $\geq 80 \%$

$<30 \%$ vs $\geq 80 \%$

Baseline pulmonary medicine

ICS and LABA: yes vs no

LABA: yes vs no

Steroids (inhaled) yes vs no

Baseline cardiac medication

Yes vs no

Cardiac history

Yes vs no
A

\section{first exacerbation}

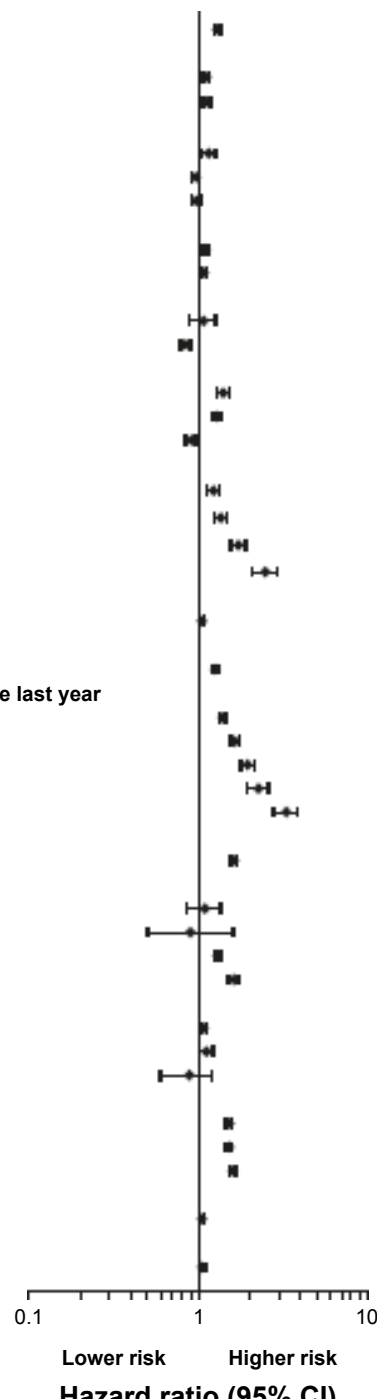

B

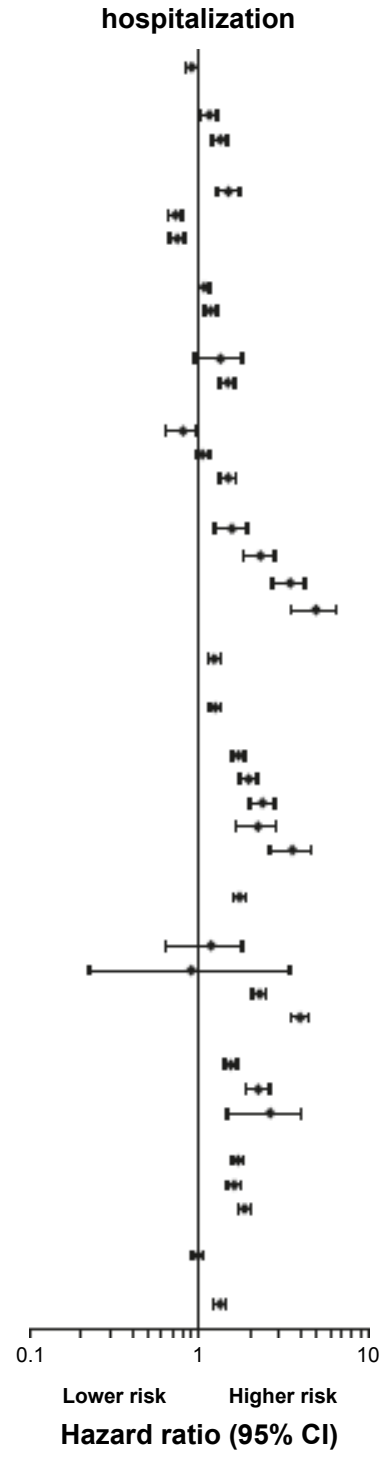

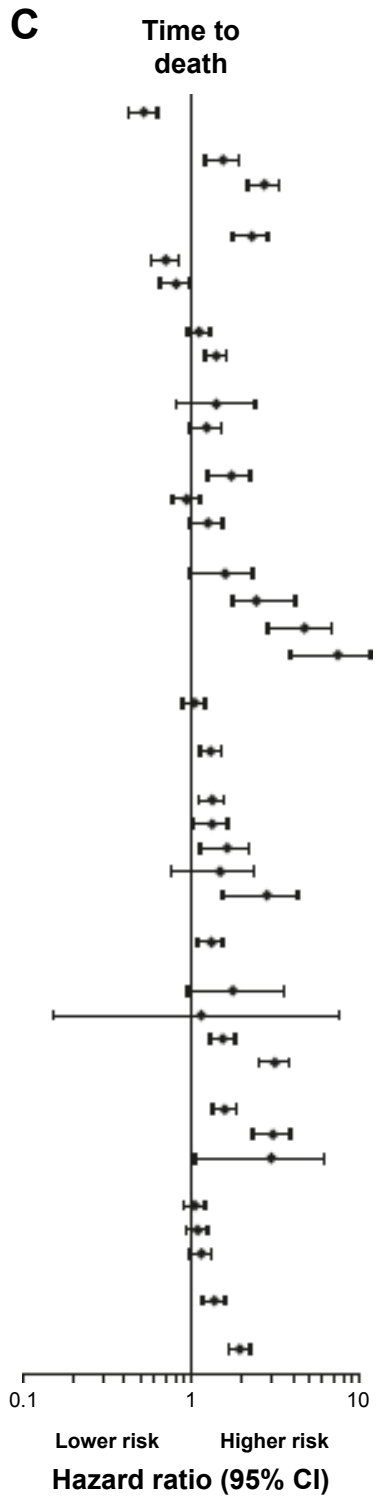

Figure SI Univariate Cox regression of time to first (A) exacerbation, (B) first hospitalization due to COPD exacerbation and (C) death (treated set).

Notes: Breathlessness mMRC descriptions: 0, not troubled with breathlessness except with strenuous exercise; I, troubled by shortness of breath when hurrying on the level or walking up a slight hill; 2, walks more slowly than people of the same age on the level because of breathlessness or has to stop for breath when walking at own pace on the level; 3 , stops for breath after walking about 100 yards [9l.44 m] or after a few minutes on the level; 4 , too breathless to leave the house or breathless when dressing or undressing.

Abbreviations: Aus, Australia; BMI, body-mass index; Euro, Europe; FEV ${ }_{1}$, forced expiratory volume in I second; FVC, forced vital capacity; ICS, inhaled corticosteroid; LABA, long-acting $\beta_{2}$-agonist; mMRC, modified Medical Research Council; NZ, New Zealand.

\section{Publish your work in this journal}

The International Journal of COPD is an international, peer-reviewed journal of therapeutics and pharmacology focusing on concise rapid reporting of clinical studies and reviews in COPD. Special focus is given to the pathophysiological processes underlying the disease, intervention programs, patient focused education, and self management protocols.

\section{Dovepress}

This journal is indexed on PubMed Central, MedLine and CAS. The manuscript management system is completely online and includes a very quick and fair peer-review system, which is all easy to use. Visit $\mathrm{http}: / / \mathrm{www}$. dovepress.com/testimonials.php to read real quotes from published authors. 